\title{
CLINICAL PROFILE OF DEEP NECK SPACE INFECTIONS IN A TERTIARY CARE HOSPITAL IN KERALA
}

\author{
G. S. Santhosh', Induprabha Yadev², Arun T. P3, S. Muneeruddin Ahmed ${ }^{4}$ \\ ${ }_{1}^{1}$ Associate Professor, Department in ENT, Government Medical College, Thiruvananthapuram. \\ ${ }^{2}$ Assistant Professor, Department of Surgery, Medical College, Trivandrum. \\ 3 Junior Resident, Department of ENT, Government Medical College, Thiruvananthapuram. \\ 4 Professor, Department of ENT, Kannur Medical College, Kannur.
}

\section{ABSTRACT}

\section{BACKGROUND}

Deep Neck Infection (DNI) is a potentially life threatening disease commonly seen in middle aged men. Associated co-morbidities like Diabetes Mellitus, Hypertension and Cardiac diseases result in life threatening complications. DNI are observed in the population who are addiction to drugs, smoking and alcoholism. DNI are associated with complications like mediastinitis, Pneumothorax, pericarditis, renal failure and multi organ failure. The present study is a prospective clinical profile study of DNIs treated in a Tertiary Care Hospital in Kerala.

Aim- To describe the profile of aetiology, clinical features and outcomes of patients with DNIs.

\section{MATERIALS AND METHODS}

50 patients attending Government Hospital attached to Government Medical College were taken to record their demographic details, etiological factors, co-morbidities, complication and nature of addiction to drugs.

\section{RESULTS}

The age group of 41 to 70 years was commonly affected by DNI with a mean age of $51.58( \pm 15.08)$. Males were commonly affected. $72 \%$ of them were males and $28 \%$ were females. History of Smoking and alcoholism accounted for more than $70 \%$ of addictions in the study. The commonest etiological factor was foreign body impaction (40\%) followed by infection of dental origin (30\%). 78\% of the patients had Co morbidities like Diabetes and Hypertension. The commonest organism cultured were Beta Hemolytic Streptococci 12 patients (24\%). In 56\% of the patients the commonly involved spaces were Retro pharyngeal, Sub Mandibular and Para pharyngeal spaces. External drainage was done in $40 \%$ and endoscopic drainage in $24 \%$ of the patients gave good outcome. The average hospital stay was 17 to 18 days.

\section{CONCLUSION}

The success in the management of DNI depends on early medical and timely surgical intervention and control of underlying systemic illness. Foreign body aero digestive tract was the most common aetiology. Diabetes mellitus was the most common associated risk factor. CECT played a very important role in diagnosis and management and should be included routinely in evaluation of DNI. Retropharyngeal space was the most commonly involved space.

\section{KEYWORDS}

Infection, Deep Neck Spaces, Ludwig's Angina, Parapharyngeal Space, Retropharyngeal Space, Endoscopy.

HOW TO CITE THIS ARTICLE: Santhosh GS, Yadev I, Arun TP, et al. Clinical profile of deep neck space infections in a tertiary care hospital in Kerala. J. Evolution Med. Dent. Sci. 2017;6(3):219-226, DOI: 10.14260/Jemds/2017/51

\section{BACKGROUND}

Deep neck space infection (DNI) means infection in the potential spaces and facial planes of the neck, either with abscess formation or cellulitis. ${ }^{1}$ Deep neck infections (DNIs) are unique among infectious diseases for their versatility and potential for severe complications. ${ }^{2}$ Complex head and neck anatomy often makes early recognition of DNIs challenging, and a high index of suspicion is necessary to avoid any delay in treatment. ${ }^{3}$ Despite the prevalence and the complications, incidence of DNI has been diminished with improved

Financial or Other, Competing Interest: None.

Submission 02-12-2016, Peer Review 26-12-2016,

Acceptance 02-01-2017, Published 09-01-2017.

Corresponding Author:

Dr. G. S. Santhosh,

Associate Professor,

Department of ENT,

Government Medical College,

Thiruvananthapuram.

E-mail:drsanths@gmail.com

DOI: $10.14260 /$ jemds $/ 2017 / 51$ diagnostic techniques and widespread availability of antimicrobial therapy. These infections are still serious and potentially life threatening today as in the past. ${ }^{4}$

Management of deep neck infections has usually been based on aggressive monitoring and management of the airway, followed by appropriate antibiotic coverage and surgical drainage, when needed. 5 The purpose of this study is to review our recent experience with DNI and emphasize the importance of early diagnosis, radiologic evaluation and appropriate treatment selection in those patients.

\section{Aim of the Study}

To describe the profile of aetiology, clinical features and outcomes of patients with deep neck space infections in Medical College Hospital, Trivandrum.

\section{Objectives of the Study}

Study the proportions of different types of neck infections. Study various aetiologies, underlying systemic diseases, complications. Study the Bacteriological profile. 


\section{MATERIALS AND METHODS}

\section{Study Design}

A prospective, Descriptive analytical study.

\section{Study Setting}

Patients diagnosed \& undergoing treatment for deep neck space infections in ENT department of Government Medical College Hospital, Trivandrum.

\section{Duration of Study}

1 year (April 2014 to March 2015).

\section{Sample Size}

40 (minimum) - (calculated using Stat Calc software with expected frequency set at $56 \%$ and worst acceptable frequency at $40 \%$; $\alpha$ error at 0.05 and $ß$ error at 0.2 ).

\section{Case Definition}

Patients diagnosed with deep neck space infection clinically and/or radiologically (XRAY/CT/USG/MRI).

\section{Inclusion Criteria}

1. All the patients diagnosed as deep neck space infection (Clinically and/or Radiologically) treated in ENT department, Govt. Medical College, Trivandrum during the course of study.

2. Patients of Both sexes.

3. Patients of all age groups.

\section{Exclusion Criteria}

Patient who were not willing to giving consent. 50 patients were included in the study according to the inclusion and exclusion criteria. Data was collected on following variables: Age, Sex, Aetiology, Clinical features, Systemic diseases, Management, Complications, Investigations, Neck spaces involved, Duration of hospital stay and Outcome of treatment. All the patients were followed up during the course of admission. Their relevant clinical history was recorded. All the patients were investigated with surgical profile and radiological imaging with CT scan. With the help of imaging, the spaces that were involved were identified. Initially empirical treatment with antibiotics was started. For all patients, sample of pus was taken either by aspiration or during Incision and drainage. Pus samples were subjected to culture and sensitivity and its results were used to change the antibiotic treatment and their results were followed up. Details about the surgical interventions done for the patients were recorded and analysed. The progression of disease during the hospital stay and management of complications were observed. Also, adequate stress was given in observing the management of underlying systemic conditions. The outcome of management was eagerly and promptly studied. All the data was analysed using suitable statistical analysis of Microsoft Excel sheet using the computer software- Statistical Package for Social Science (SPSS) version 22 that include percentage analysis and graphical analysis.

\section{RESULTS}

50 patients with Deep Neck Space Abscess were examined in the Department of ENT of Medical College Hospital during the period between April 2014 and March 2015 and included in the present study. The age of the Patients ranged from below 20 years to above 70 years with a mean age of 51.58 years $( \pm 15.08)$ (range $14-75$ years). 35 patients $(70 \%)$ belonged to the age group of 41 to 70 years (Table 1), (Fig 1).

\begin{tabular}{|c|c|c|}
\hline Age Group & Frequency & Percent \\
\hline$<20$ & 2 & 4.0 \\
\hline $21-30$ & 3 & 6.0 \\
\hline $31-40$ & 6 & 12.0 \\
\hline $41-50$ & 12 & 24.0 \\
\hline $51-60$ & 11 & 22.0 \\
\hline $61-70$ & 12 & 24.0 \\
\hline$>70$ & 4 & 8.0 \\
\hline
\end{tabular}

Table 1. Showing the age distribution among the patients of DNI $(n=50)$

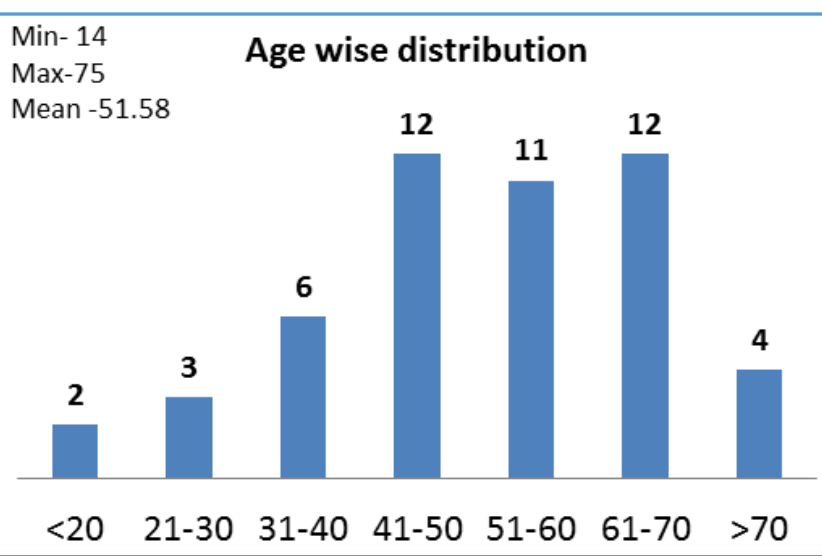

Figure 1. Showing the age distribution of DNI patients ( $n=50)$

Among the 50 patients there were $36(72 \%)$ male and 14 $(28 \%)$ female patients, with a female-to-male ratio of $0.38 / 1$, (Table 2).

\begin{tabular}{|c|c|c|}
\hline Sex & Frequency & Percentage \\
\hline $\mathrm{F}$ & 14 & 28.0 \\
\hline $\mathrm{M}$ & 36 & 72.0 \\
\hline \multicolumn{3}{|c|}{ Table 2. Showing the Gender distribution in } \\
DNI patients ( $\mathrm{n}=50)$ \\
\hline
\end{tabular}

Among the 50 patients the history of foreign body ingestion was seen in 20 patients (40\%), followed by odontogenic cause which was seen in 15 patients $(30 \%)$, (Table 3), (Fig 2).

\begin{tabular}{|c|c|c|}
\hline Aetiology & Frequency & Percent \\
\hline FB & 20 & 40.0 \\
\hline Lymphadenitis & 3 & 6.0 \\
\hline Odontogenic & 15 & 30.0 \\
\hline Parotitis & 1 & 2.0 \\
\hline Post-surgical & 1 & 2.0 \\
\hline Quinsy & 1 & 2.0 \\
\hline Unknown & 4 & 8.0 \\
\hline URI & 5 & 10.0 \\
\hline Table 3. Showing the Etiological factors in DNI patients \\
$(n=50)$
\end{tabular}




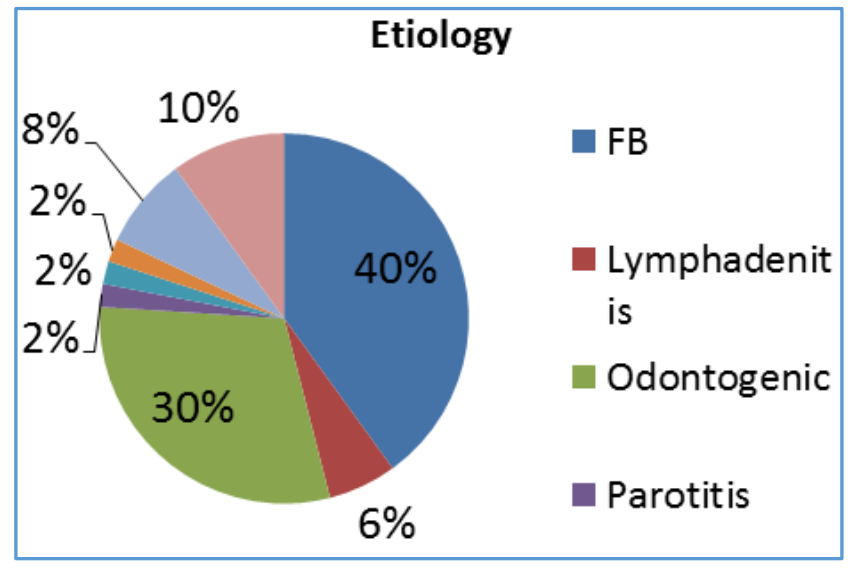

Figure 2. Showing the Etiological factors in pie chart $(n=50)$

On elicitation of history 27 patients (54\%) had addictions to smoking and alcohol and Pan Chewing. 23 patients and no such habits (Table 4).

\begin{tabular}{|c|c|c|}
\hline Addiction & Frequency & Percent \\
\hline Alcohol & 4 & 8.0 \\
\hline Alcohol + Smoking & 14 & 28.0 \\
\hline Alcohol + Smoking + Pan & 2 & 4.0 \\
\hline NIL & 23 & 46.0 \\
\hline Pan chewing & 1 & 2.0 \\
\hline Smoking & 6 & 12.0 \\
\hline Table 4. Showing incidence of Addictions (n=50) \\
\hline
\end{tabular}

24 patients (48\%) had associated Diabetes Mellitus as co morbidity. There were 15 patients (30\%) with Hypertension and 7 patients (14\%) with heart disease (Table 5).

\begin{tabular}{|c|c|c|}
\hline Co morbidities & Frequency & Percent \\
\hline Diabetes mellitus & 24 & 48.0 \\
\hline Hypertension & 15 & 30.0 \\
\hline Heart disease & 7 & 14.0 \\
\hline Renal & 3 & 6.0 \\
\hline Table 5. Showing the Co morbidities among DNI patients \\
$(\mathbf{n = 5 0 )}$
\end{tabular}

Pain was the most common presenting complaint followed by dysphagia (70\%), fever (66\%), neck swelling (48\%), odynophagia (42\%), Trismus (22\%), drooling of saliva, hot potato voice, hoarseness ( $12 \%$ each), dyspnoea (6\%), otalgia and stridor (2\% each), (Table 6).

\begin{tabular}{|c|c|c|}
\hline Symptom & Frequency & Percentage \\
\hline Pain & 50 & 100 \\
\hline Dysphagia & 35 & 15 \\
\hline Fever & 33 & 17 \\
\hline Swelling & 24 & 26 \\
\hline Odynophagia & 21 & 29 \\
\hline Trismus & 11 & 39 \\
\hline Drooling & 6 & 44 \\
\hline Hot potato voice & 6 & 44 \\
\hline Hoarseness of voice & 6 & 44 \\
\hline Dyspnoea & 3 & 47 \\
\hline Stridor & 1 & 49 \\
\hline Earache & 1 & 49 \\
\hline
\end{tabular}

Table 6. Showing the incidence of various symptoms in DNI patients $(\boldsymbol{n}=50)$
Radiological evaluation with CT scan was performed in all the patients to identify the exact location, extent and nature (cellulitis or abscesses) of the infections. X- Ray soft tissues neck (either lateral or AP) was taken for all patients. It was supported with CT scan of Neck (plain \& contrast) in 38 patients $(76 \%)$ and with ultrasonography in 20 patients (40\%). Neck ultrasonography was performed less compared to the CT (Table 7).

\begin{tabular}{|c|c|c|}
\hline Radiological Investigation & Frequency & Percent \\
\hline X ray neck (Lat./AP) & 50 & 100.0 \\
\hline CT NECK (plain \& contrast) & 38 & 76.0 \\
\hline Ultrasonography neck & 20 & 40.0 \\
\hline \multicolumn{3}{|c|}{$\begin{array}{l}\text { Table 7. Showing the Radiological Investigations of DNI } \\
\text { patients }(n=50)\end{array}$} \\
\hline
\end{tabular}

The results of bacterial cultures were available for 19 (38\%) of the 50 cases. Anaerobic and aerobic cultures were obtained. Most common organism isolated was Beta Haemolytic Streptococci 12 patients (24\%), (Table 8).

\begin{tabular}{|c|c|c|}
\hline Pus Culture & Frequency & Percent \\
\hline B Haemolytic streptococci & 12 & 24.0 \\
\hline NIL & 31 & 62.0 \\
\hline Pseudomonas aeruginosa & 2 & 4.0 \\
\hline Staphylococcus aureus & 4 & 8.0 \\
\hline sterile & 1 & 2.0 \\
\hline
\end{tabular}

In the present study, according to clinical, surgical and imaging findings, $32(64 \%)$ of patients had one space affected. The most common site involved was the retropharyngeal space $(48 \%)$, followed by the parapharyngeal space (32\%), the sub-Mandibular space (32\%), the pretracheal space (8\%), the carotid space (6\%), the parotid space, masticatory space and posterior cervical space ( $2 \%$ each). In 18 patients (36\%), the infection involved more than one space. If 2 or more spaces were concurrently involved in a significant way, they were classified as extended space infections. The diagnostic criteria of Ludwig's angina were defined as the simultaneous involvement of the sublingual, Submandibular and sub mental spaces, either as cellulitis or abscesses. 7 patients $(14 \%)$ were evaluated as Ludwig's angina, and 11 patients (22\%) were evaluated as extended spaces (Fig. 3).

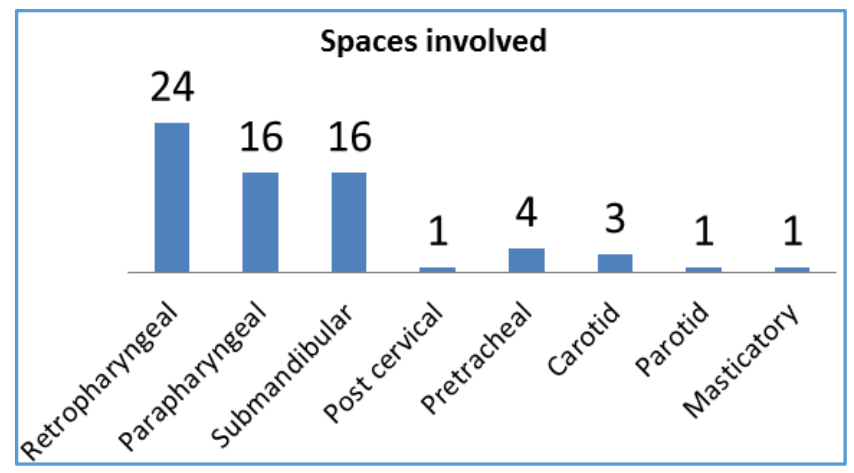

Figure 3. Showing the various spaces affected in the study $(n=50)$ 
Among the Retropharyngeal space infections (24), 9 patients had extensions to other spaces which included parapharyngeal (4), carotid (1), 1 case extending to both, 1 case extending to carotid and posterior cervical space and 2 cases to pretracheal space. 18 patients had multiple spaces involved and 32 patients had one space involved (Fig 4 \& 5).

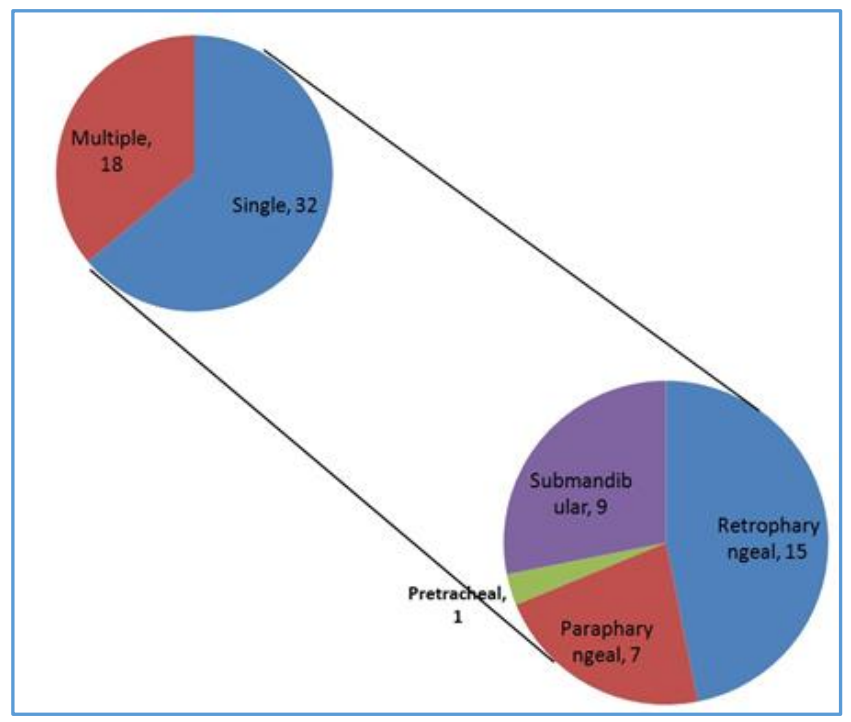

Chart 4. Showing the comparison between single and multiple spaces involvement in Retropharyngeal space DNI $(n=50)$

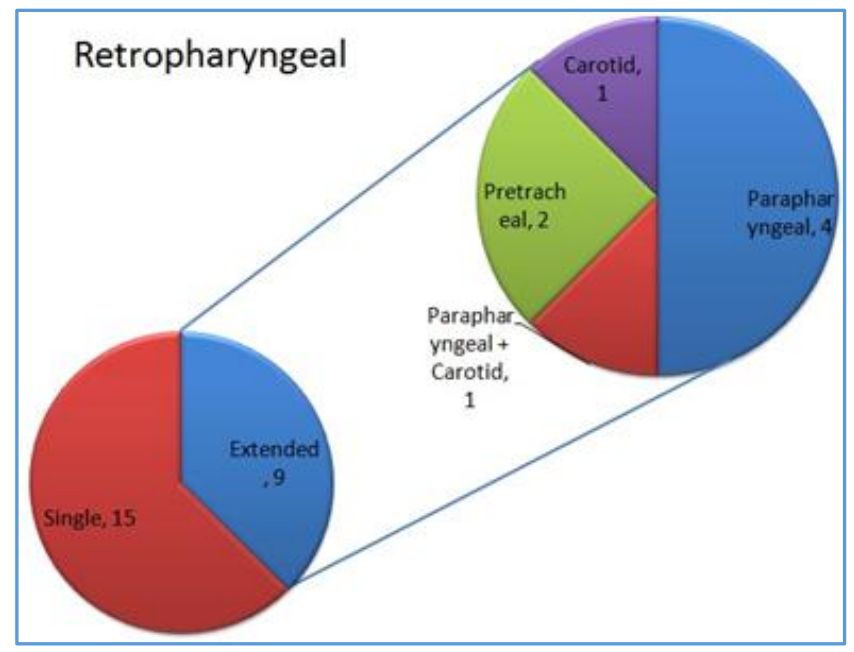

Figure 5. Showing the involvement of retropharyngeal space alone and extension to other spaces $(n=50)$

Among the Submandibular space DNI of 7cases with local extension, 4 were to sublingual and sub mental spaces contributing to Ludwig's abscess, 2 to parapharyngeal space and 1 to pretracheal space (Fig. $6 \& 7$ ).

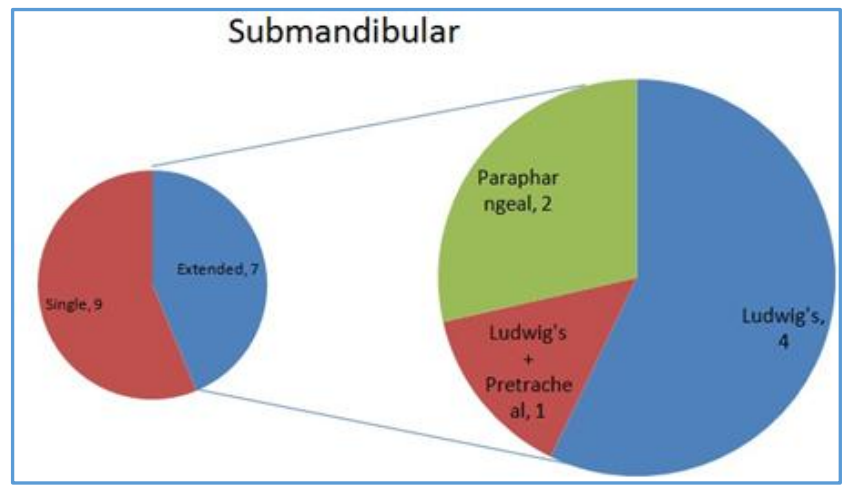

Figure 6. Showing Submandibular space and extensions $(n=50)$

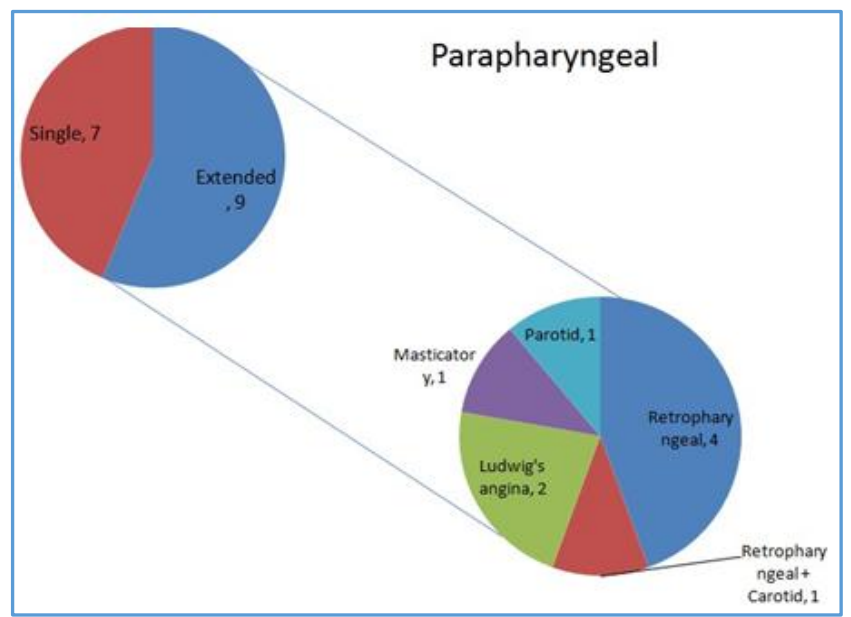

Figure 7. Showing Parapharyngeal space DNI and its extension to other spaces $(n=50)$

All patients received antimicrobial therapy after admission. The antibiotic regimen had to cover mostly grampositive aerobes and anaerobes implicated in deep neck infections, and also considering the rising incidence of polymicrobial infections. Empirical intravenous antibiotics (Benzyl penicillin, $\beta$-lactam $/ \beta$-lactamase-resistant antibiotics, the third-generation cephalosporin antibiotics, metronidazole, gentamicin) were administered before the culture results were available, and then the antibiotics regimen was modified based on the culture and sensitivity results. Mostly chosen antibiotic was parenteral ampicillin 4 times per day plus metronidazole 3 times per day plus gentamicin 3 times. The second most preferred option was cefoperazone sulbactam 2 times per day plus metronidazole 3 times per day. Supportive medical treatments (analgesics and antipyretics, intravenous fluids, mouthwashes, intravenous steroids) were also given. Considering the clinical condition and imaging diagnosis, 11 patients (22\%) were treated with intravenous antibiotic therapy alone, whereas surgical intervention was required in 39 patients (78\%). Distribution of our treatment approach is shown in following chart and table. The surgical procedures ranged from a simple drainage by a topical anaesthesia to a wide incision and hypopharyngoscopy assisted drainage under general anaesthesia (Fig. $8 \&$ 9). 


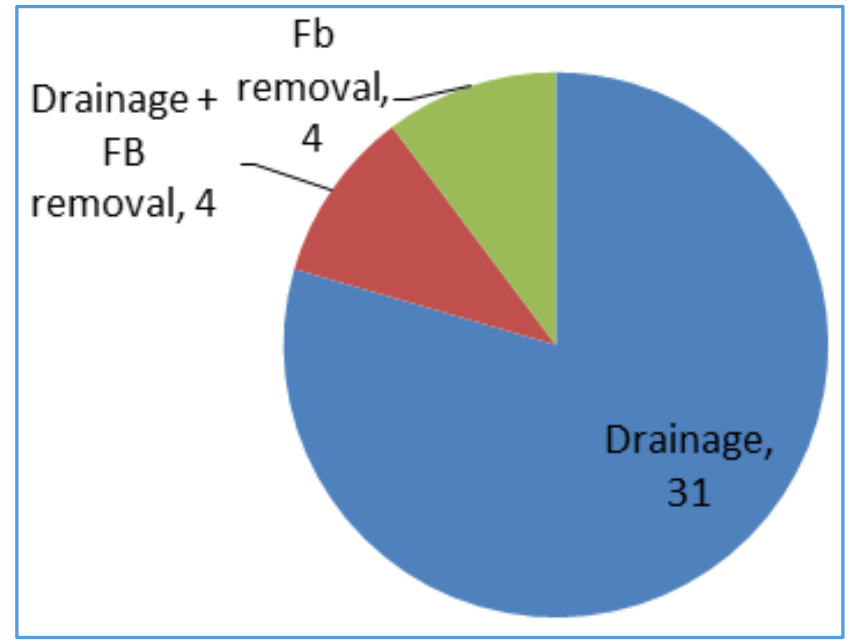

Figure 8. Showing the procedures adopted in the treatment $(n=50)$

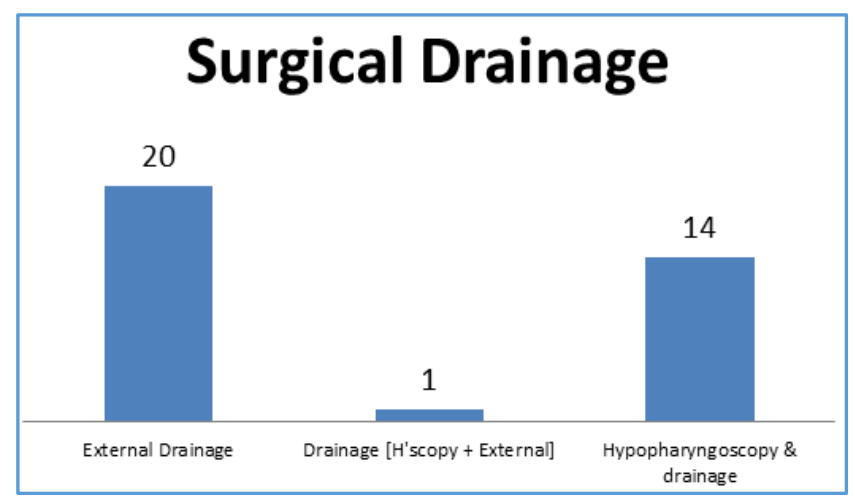

Figure 9. Showing the methods of surgical intervention $(n=50)$

There were 9 patients (18\%) who developed lifethreatening complications. Upper airway obstruction (4 patients; 8\%) was the most commonly occurring complication and two of them required tracheostomy. Descending mediastinitis was seen in 3 patients $(6 \%) .2$ patients $(4 \%)$ developed pleural effusion. The other rare but serious complications were sepsis, pneumonia, internal jugular vein thrombosis, myocardial infarction, oesophageal perforation (each in 1 patient, 2\%). 1 patient also developed unilateral vocal cord palsy which later on improved with resolution of DNI (Fig 10).

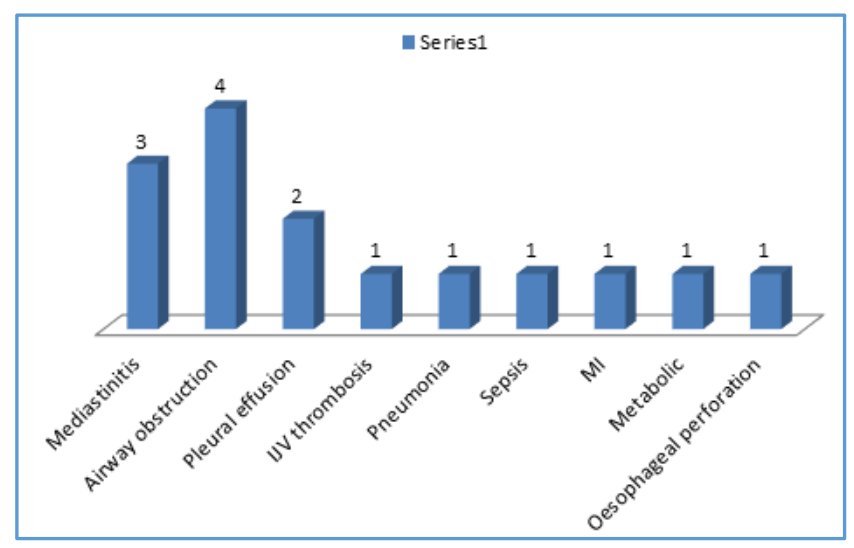

Figure 10. Showing the various complications observed in the study $n=50$ )
4 out of $18(22 \%)$ multiple space infections developed complications whereas only 5 out of 32 (15.6\%) single space infections developed complications (Fig. 11), (Table 9).

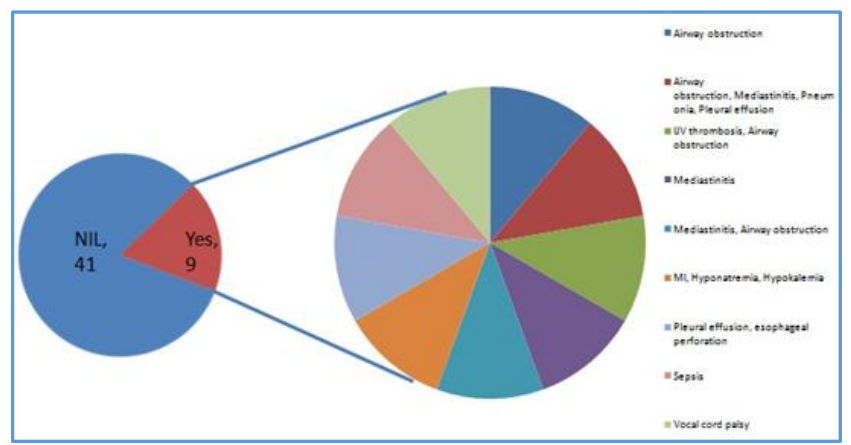

Figure 11. Showing the relation between single and multiple spaces involvement and complications $(n=50)$

\begin{tabular}{|c|c|c|}
\hline \multirow{2}{*}{ No. of Spaces } & \multicolumn{2}{|c|}{ Complication } \\
\cline { 2 - 3 } & NIL & YES \\
\hline Multiple & 14 & 4 \\
\hline Single & 27 & 5 \\
\hline
\end{tabular}

Table 9. Showing the incidence of complications in relation to single or multiple space involvement $(n=50)$

The mean duration of hospital stay was $2.14 \pm 1.14$ weeks (range 1 - 6 weeks). All the patients attained complete cure and Crude mortality was nil; all patients were discharged in stable condition (Fig 12).

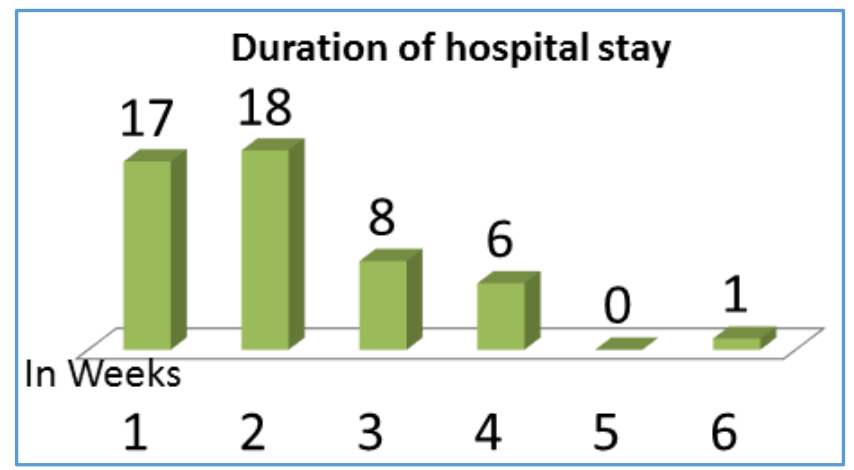

Figure 12. Showing the duration of Hospital stay $(n=50)$

\section{DISCUSSION}

\section{Age Distribution}

In the present study, most of the patients belonged to $5^{\text {th }}$ and 7 th decade. $54 \%$ of the patients are above the age of 50 and $46 \%$ of patients were younger than 50 years. The mean age was 51.58 years. The prevalence of DNI is comparatively high in elderly adults in this study. This varied in comparison with studies by Chen et al (43.2 yrs.), ${ }^{1}$ Wang et al (41.8 yrs.), ${ }^{2}$ Huang et al (49.5 yrs.), ${ }^{3}$ Bottin et al (51 yrs.), Sethi and Stanley (45.5), ${ }^{5}$ Salih Bakir et al (25.1 yrs.). ${ }^{6}$ The variation probably may be attributed to the non inclusion of paediatric population with DNI who were treated in paediatrics department and not in our department. The youngest patient was being only 14 yrs. old.

\section{Sex Distribution}

The sex comparison showed a definite predominance in males (F: M -0.38). This is comparable to different studies like 
Chen et al (0.37), ${ }^{1}$ Wang et al (0.49), ${ }^{2}$ Huang et al (0.69), ${ }^{3}$ Bottin et al (0.5),4 Sethi and Stanley $(0.83)^{5}$ which unanimously showed a male preponderance.

\section{Aetiology}

The most common cause of DNI in this study is foreign body upper aero digestive tract $(40 \%)$. But most of the studies show odontogenic cause as the most common cause like Huang et $\mathrm{al}^{3}$ found $(42 \%, 2004)$, Parhiscar and Har-El ${ }^{7}$ $(43 \%, 2001)$, Marioni et $\mathrm{al}^{8}(38.8 \%, 2008)$, Eftekharian et $\mathrm{al}^{9}$ $(49 \%, 2009)$ and Bottin et $\mathrm{al}^{4}(42 \%, 2003)$. In this study, odontogenic causes are the second most common aetiology (30\%). $52 \%$ of the smokers and $66.67 \%$ of pan chewers had odontogenic cause for DNI. Odontogenic infections were the most common cause of multi space infections which is in similarity with study by Linjian et al 10 Prior to the extensive use of antibiotics, many studies observed that tonsillopharyngeal infections attributed to most DNI cases (about $70-80 \%),{ }^{11}$ compared to present scenario where there is a reduced incidence (8-16\%) in Pharyngo-tonsillar aetiology. $3,4,7,9,11$ In this study they contributed to only $12 \%$. Certain studies show that upper airway infections are common causes of DNI.12-15 Cervical lymphadenitis contributed to $6 \%$. Parotitis and surgery contributed to $2 \%$ each. $8 \%$ patients had no detectable aetiology. There was 1 patient with tuberculous aetiology. This patient developed retropharyngeal tuberculous lymphadenitis and was suspected in the absence of response to antibiotics. Hence tuberculosis must be kept in mind especially in DNI Addictions According to this study, 54\% of patients had addictions, most of them were smokers. There is a significant relationship between addiction and requirement of surgical interventions.

\section{CO Morbidities}

$54 \%$ of patients had underlying co morbidities. Diabetes mellitus was the most common (48\%). DM was reported as the most common risk factor to be associated with deep neck infections by Huang et $\mathrm{al}^{3}$ and observed a major incidence (30.3\%). Though diabetics didn't show any significant relation with requirement of surgical intervention, people with both diabetes and hypertension showed a significant relationship with surgical intervention. $50 \%$ of people with multiple space infection were diabetic whereas only $46.875 \%$ of people with single space infection were diabetic.Therefore there is a significant increase in multiple space involvement in patients with diabetes. $33.33 \%$ of diabetics developed complications whereas only $3.8 \%$ of non diabetics developed complications. The duration of hospital stay was more in diabetics. From the above comparisons, diabetics had prolonged hospitalizations similar to many studies, $[2,3,15,16,17]$ needed surgical intervention more often,[3] showed poor response to conservative medical management,[15,17] and had higher chance of developing complications.[3,15,17] Hence, diabetics with DNI must be managed more aggressively with medical and surgical intervention and careful blood glucose monitoring.[17]

\section{Clinical Features}

According to most of the recent studies, pain and swelling of the neck are the most prevalent symptoms.[2,15,16,18,19,20] In this study, pain was the most common presenting complaint, which was followed by dysphagia and neck swelling. Presenting complaints varied according to the space involved. Sub Mandibular and Ludwig's abscesses most commonly presented with neck swelling (93\%), whereas retropharyngeal and parapharyngeal spaces most commonly presented as dysphagia (93\% and $85 \%$ when only single space involvement was considered).

\section{Imaging}

The advancements in imaging modalities have favourably contributed in effective management of DNI. CECT scan is very sensitive (91\%) and highly useful to identify the extent of involvement and differentiate an abscess from cellulitis. ${ }^{11}$ Therefore it helps to decide on the need for a surgical intervention. ${ }^{17}$ Cases with radiological findings suggestive of cellulitis are supposed to respond earlier to medical treatment and have better prognosis compared to abscesses which are more aggressive and may need surgical treatment. 10 However, ultrasonography does not provide good anatomical data and may fail to identify deeply located abscess and hence does not help in deciding on surgical intervention. ${ }^{17}$ Magnetic resonance imaging and CECT have similar prognostic value, but MRI is more expensive and requires prolonged scanning time, hence not routinely performed in DNI.17 Even though far inferior to CECT, a routine X- ray was taken for all the patients as a cheaper initial investigation which helped to identify DNI with poorer anatomical details. Based on this evidence, we did CECT for $76 \%$ of our patients which were conclusive.

\section{Spaces Involved}

According to the findings, retropharyngeal space was the most common space involved. This differed in comparison with various studies, $[9,11,18,19]$ among which sub Mandibular space was the most commonly involved space. This can be explained by the fact that the most common etiological factor was foreign body upper aero-digestive tract which would contribute to the retropharyngeal space involvement. Patients with multiple space involvement developed complications, needed surgical intervention and had prolonged hospital stays compared to single space infection. All patients with multiple space involvement needed surgical intervention. $22 \%$ of patients with multiple space infection developed complications as compared to only $15.6 \%$ of patients with single space infection. $44.4 \%$ of patients with multiple space infection needed hospital stay more than 2 weeks compared to only $21 \%$ in single space infections. This was comparable to other studies.[1,2,3,9]

\section{Medical \& Surgical Management}

As per most of the studies, management of DNI involves prompt surgical drainage via an external approach.[2,3,4,7,9,11] But, Plaza Mayor et al[10] advocated medical management with broad-spectrum intravenous antibiotics, high-dose iv or oral corticosteroids for most of the patients with DNI. In this study, 11 patients (22\%) were managed successfully with medical treatment alone. The remaining were managed with surgical intervention along with medical management. In patients with cellulitis, infection usually is controlled with iv antibiotics and steroids alone.[8,9,20] Medical therapy alone may be sufficient in minimal abscess without any complications. $[8,9,10]$ Patients with less severe infection who 
were managed with medical management alone develop complications only rarely.[9,10] Empiric antibiotic therapy is started even before the pus culture report is obtained. This covers most gram-positive, anaerobic, as well as $\beta$-lactamaseproducing bacteria.[11] In this study, it consisted of Benzyl penicillin, $\beta$-lactam $/ \beta$-lactamase-resistant antibiotics, the third-generation cephalosporin antibiotics, metronidazole, gentamicin. The antibiotics were changed according to culture and sensitivity once the results were obtained. Majority of the patients did not need a change in antibiotic after culture and sensitivity. These patients were also managed with supportive measures according to symptoms, which included analgesics, antipyretics, intravenous fluids and mouthwashes. Intravenous steroids (Dexamethasone 8 mg tid) were used in most of the patients for a short duration for controlling local oedema and dyspnoea. The need for a surgical intervention was largely decided by imaging findings and progression of medical management. In patients with CECT suggestive of abscess formation, early surgical intervention is necessary [3]. Surgical intervention is also essential in airway compromise, sepsis and inadequate response to antibiotics within 48 hours. ${ }^{[8,9,20]} 78 \%$ (39 cases) of patients needed surgical intervention out of which 35 cases needed drainage of abscess either hypopharyngoscopy guided or external drainage. Four patients developed upper airway obstruction out of which two needed tracheostomy whereas the other two were relieved gradually with drainage of abscess and did not need tracheostomy.

\section{Complications}

The important complications are mediastinitis, pleural effusion, airway obstruction, IJV thrombosis, sepsis, pericarditis, pneumonia, carotid artery rupture, hepatic failure, shock and disseminated intravascular coagulopathy.[3,4] The mortality increases with increased incidence of complications. ${ }^{[4]}$ Descending mediastinitis is one of the most life-threatening complications of DNI.[16] In this study, the most frequent complication was airway obstruction (4 cases; $8 \%$ ) followed by mediastinitis (3 cases; 6\%).All the cases with airway obstruction (4 cases) had retropharyngeal involvement and two had additional parapharyngeal space involvement also. The underlying aetiology was foreign body in all cases of mediastinitis. Two of them recovered with IV antibiotics and supportive measures alone. One patient needed surgical intervention in the form of cervical incision approach with help of cardiovascular thoracic surgery dept. and recovered. Surgical treatment is essential in patients with mediastinitis [21]. Approach by cervical incision has lower risk compared to Thoracotomy approach. Moreover, Thoracotomy is more invasive and may worsen the prognosis [21]. According to studies, Kinzer et al [21] used collar mediastinotomy approach, whereas Wheatley et al. [22] preferred transthoracic mediastinal drainage and both of them had good results with their respective approaches. There was 1 patient with IJV thrombosis who improved with drainage of the abscess and along with IV antibiotics. Anticoagulant therapy was not used for this patient.

\section{Microbiology}

A positive pus culture was obtained only in $36 \%$ of cases. $24 \%$ patients had B haemolytic streptococci, $8 \%$ had staphylococcus aureus and 4\% showed pseudomonas aeruginosa. The reason for small sample size is due to difficulty in obtaining pus for culture and sensitivity from the retropharyngeal abscesses drained via a hypopharyngoscopy approach. Conclusions could not be made due to limited number of samples. The most common gram positive organisms were streptococcus and staphylococcus which is similar to the studies by Sethi and Stanley 1994, Sakaguchi et al 1997, Brook 1987, Parhiscar and Har El 2001,el Sayed and al Dousary 1996 and Bottin et al.[4,5,7,23,24,25]

\section{Duration of Hospital Stay}

The mean duration of hospital stay was $2.14 \pm 1.14$ weeks (range 1 - 6 weeks) which was similar in other studies.[4,19,24] The duration was prolonged in case of multiple space infection and in case of complications.

\section{CONCLUSION}

The successful management of Deep neck space infection depends on early medical and timely surgical intervention and control of underlying systemic illness. DNI was more common in men and in older age group. Foreign body aero digestive tract was the most common aetiology. Diabetes mellitus was the most common associated risk factor. CECT played a very important role in diagnosis and management and should be included routinely in evaluation of DNI. Retropharyngeal space was the most commonly involved space. Early empirical antibiotic therapy, pus culture and sensitivity, surgical intervention is the cornerstones of management. Upper airway obstruction, followed by mediastinitis was the most common complications. All the patients attained cure.

\section{Limitations}

This study does not include the cases admitted in the paediatric as well as oro- maxillofacial surgery department and hence does not mirror the exact population study. Limited number of samples obtained for culture and sensitivity restricts the study from commenting on the microbiological profile successfully.

\section{Recommendations}

Appropriate imaging modality must be used for early diagnosis and management. This study recommends CECT for an early and accurate diagnosis. Early empirical antibiotic therapy is very essential, this study recommends a combination of Benzyl penicillin, $\beta$-lactam $/ \beta$-lactamaseresistant antibiotics, third-generation cephalosporin antibiotics and metronidazole and gentamicin-

1. Tuberculous aetiology must be considered in case of DNI not responding to initial medical and surgical management.

2. Underlying systemic illnesses which can contribute to immune dysfunction must be managed simultaneously for best results.

\section{REFERENCES}

[1] Chen MK, Wen YS, Chang CC, et al. Predisposing factors of life-threatening deep neck infections: logistic regression analysis of 214 cases. J Otolaryngol 1998;27(3):141-4. 
[2] Wang LF, Kuo WR, Tsai SM, et al. Characterisation of life-threatening deep cervical space infections: a review of 196 cases. Am J Otolaryngol 2003;24(2):111-7.

[3] Huang TT, Liu TC, Chen PR, et al. Deep neck infection: analysis of 185 cases. Head Neck 2004;26(10):854-60.

[4] Bottin R, Marioni G, Rinaldi R, et al. Deep neck infection: a present day complication. A retrospective review of 83 cases (1998-2001). Eur Arch Otorhinolaryngol 2003;260:576-9.

[5] Sethi DS, Stanley RE. Deep neck abscesses-changing trends. J Laryngol Otol 1994;108(2):138-43.

[6] Bakir S, Tanriverdi MH, Gün R, et al. Deep neck space infections: a retrospective review of 173 cases. American Journal of Otolaryngology 2012;33:56-63.

[7] Parhiscar A, Har-El G. Deep neck abscess: a retrospective review of 210 cases. Ann Otol Rhinol Laryngol 2001;110(11):1051-4.

[8] Marioni G, Rinaldi R, Staffieri C, et al. Deep neck infection with dental origin: analysis of 85 consecutive cases (2000-2006). Acta Otolaryngol 2008;128(2):2016.

[9] Eftekharian A, Roozbahany NA, Vaezeafshar R, et al. Deep neck infections: a retrospective review of 112 cases. Eur Arch Otorhinolaryngol 2009;266(2):273

[10] Huang L, Jiang B, Cai X, et al. Multi-Space infections in the head and neck: do underlying systemic diseases have a predictive role in life-threatening complications. Journal of oral and maxillofacial surgery: official journal of the American Association of Oral and Maxillofacial Surgeons 2015;73(7):1320.e1-10.

[11] Mayor PG, Martinez-San MJ, Martinez-Vidal A. Is conservative treatment of deep neck space infections appropriate? Head Neck 2001;23(4):126-33.

[12] Ungkanont K, Yellon RF, Weissman JL, et al. Head and neck space infections in infants and children. Otolaryngol Head Neck Surg 1995;112(3):375-82.

[13] Çağlı S, Yüce İ, Güney E. Deep neck infections: results of 50 cases. Erciyes Med J 2006;28:211-5.
[14] Miman MC, Öncel S, Kalcıŏglu T. Derin boyun enfeksiyonlarına klinik yaklaşım. KBB İhtisas Dergisi 2001;8:206-13.

[15] İynen İ, Şan İ, Bozkuş F. Deep neck infection: an analysis of 82 patients. J Harran Univ Med Fac 2009;6:25-8.

[16] Lee JK, Kim HD, Lim SC. Predisposing factors of complicated deep neck infection: an analysis of 158 cases. Yonsei Med J 2007;48(1):55-62.

[17] Lin HT, Tsai CS, Chen YL, et al. Influence of diabetes mellitus on deep neck infection. J Laryngol Otol 2006;120(8):650-4.

[18] Stalfors J, Adielsson A, Ebenfelt A, et al. Deep neck space infections remain a surgical challenge. A study of 72 patients. Acta Otolaryngol 2004;124(10):1191-6.

[19] Boscolo-Rizzo P, Marchiori C, Zanetti F, et al. Conservative management of deep neck abscesses in adults: the importance of CECT findings. Otolaryngol Head Neck Surg 2006;135(6):894-9.

[20] Crespo AN, Chone CT, Fonseca AS, et al. Clinical versus computed tomography evaluation in the diagnosis and management of deep neck infection. Sao Paulo Med J 2004;122(6):259-63.

[21] Kinzer S, Pfeiffer J, Becker S, et al. Severe deep neck space infections and mediastinitis of odontogenic origin: clinical relevance and implications for diagnosis and treatment. Acta Otolaryngol 2009;129(1):62-70.

[22] Wheatley MJ, Stirling MC, Kirsh MM, et al. Descending necrotizing mediastinitis: transcervical drainage is not enough. Ann Thorac Surg 1990;49(5):780-4.

[23] Brook I. Microbiology of abscesses of the head and neck in children. Ann Otol Rhinol Laryngol 1987;96(4):42933.

[24] Sakaguchi M, Sato S, Ishiyama T, et al. Characterization and management of deep neck infections. Int J Oral Maxillofacial Surg 1997;26(2):131-4.

[25] el-Sayed Y, al Dousary S. Deep-neck space abscesses. J Otolaryngol 1996;25(4):227-33. 